\title{
Synapsin-I Expression in the Rattus norvegicus Pup's Brain from Rat's Maternal Death Model
}

\author{
Nur Maziyah Hurin'in, ${ }^{1}$ Hermanto Tri Joewono ${ }^{2}$, Widjiati ${ }^{3}$ \\ ${ }^{1}$ Postgraduate Student of Reproductive Health Science, Faculty of Medicine, ${ }^{2}$ Department of Obstetric and \\ Gynecology, Faculty of Medicine,, ${ }^{3}$ Department of Embryology, Faculty of Veterinary Medicine, Airlangga \\ University, Surabaya, Indonesia
}

\begin{abstract}
Maternal mortality could be a neonatal stressor that activated the HPA axis to secret glucocorticoids as a marker of stress. Brain development took place rapidly in the first 1,000 days of life. Synapsin-I was involved in the early development of the brain's nervous system. The purpose of this study was to analyze the impact of separation of Rat's pup and mothers as a maternal death model on the expression of synapsin-I in the cerebrum and cerebellum of 3 days old Rattus norvegicus pups. The control group (K1) consisted of newborn Rattus norvegicus which remained with the mother, while the treatment group (K2) consisted of newborn Rattus norvegicus which was separated from the mother. After 3 days of observation, Rattus norvegicus pups from each parent were taken with the heaviest, medium, and lowest weights to be sacrificed and examined by imonohistochemical of synapsin-I expression. Analysis of the Mann Whitney test for synapsin-I expression in Rattus norvegicus cerebrum showed a significant difference between the control group and the treatment group with a value of $\mathrm{p}=0,000(\mathrm{p}<0.05)$. Independent $\mathrm{T}$ test analysis of synapsin-I expression in Rattus norvegicus cerebellum also showed a significant difference between the control group and the treatment group with a value of $p=0,000(p<0.05)$. Synapsin-I expressions in the cerebrum and cerebellum of Rattus norvegicus pups that separated from the mothers were lower than those that not separated from the mothers.
\end{abstract}

Keywords: maternal death model, synapsin-I, cerebrum, cerebellum

\section{Introduction}

Maternal Mortality Rate (MMR) was an indicator of assessment of maternal health programs. The case of maternal mortality, also called maternal death, occurs in pregnant women on a number of certain days starting during pregnancy until after the termination of pregnancy or 42 days after delivery. This could be due to caused that were related or exacerbated by pregnancy, handling pregnancy, and/or handling labor. Accidents or incidental events were not the cause of maternal death. Many maternal deaths occur during labor and postpartum. ${ }^{1-2}$

\section{Corresponding Author:}

Prof. Dr. Widjiati, M.Sc, DVM;

Mulyorejo, Surabaya, East Java, Indonesia

Phone: +6281330649116

Email: widjiati@fkh.unair.ac.id
In 1990-2015, the Maternal Mortality Rate (MMR) globally decreased by $44 \%$, from 385 cases to 206 cases per 100,000 live birth rates. The decline was still far from the Millennium Development Goal 5a target. This number also did not meet the objectives of the 2030 Sustainable Development Goals (SDG'S) program which targeted maternal mortality rates are 70 of 100,000 live births. ${ }^{3}$ Since 1991 to 2007 , Based on the Indonesian Health Profile (2016), the number of MMR in Indonesia has decreased, from 390 to 228 from 1991 to 2007. According to the Bureau of Communication and Community Services of the Health Ministry of Republic Indonesia, the maternal mortality rate in Indonesia was 4,999 in 2015 to 4,912 in 2016 and 2017 (first semester) decreased to 1,712 cases. Based on the East Java Health Office, the maternal mortality rate in East Java Province on 2015 reached 89,6 of 100,000 live births and on 2016 it increased to 91 of 100,000 live births.

Maternal mortality at the beginning of a child's life could result in loss of contact between mother and 
baby and disruption of breastfeeding which would affect the child survival. ${ }^{2}$ Interaction between mother and baby could occur through touch, skin contact, and eye contact which provided a calm effect. Reduced or even lost contact between mother and baby due to maternal death could result in babies having higher cortisol levels than babies who were directly treated by their mothers. Therefore, this might be a cause of neonatal stress at the beginning of a child's life. ${ }^{7}$

Child's brain growth and development took place quickly starting in the womb, which was on the first 1,000 days of the children life up to 3 years old. Some important developmental processes include neuron proliferation, synaptic formation, myelination, and axons and dendrites growth. A good brain development and growth would affect cognitive, social, and emotional abilities as the foundation and the development of future generations. The brain consisted of the cerebrum which plays a role in cognitive and affective functions as well and the cerebellum which played a role in motor, cognitive, emotional, and behavioral development. ${ }^{8-9}$ Synapsin-I was the main isoform in neurons which were phosphoproteins that bound to synaptic vesicles. Synapsin-I played a role in synaptogenesis and neuronal plasticity, including synapses development, terminal nerve formation, and neurotransmitter expenditure. ${ }^{10}$ Reduced Synapsin-I would result in disruption of axon differentiation, neurit growth, inhibition of formation and synapses, and allowed nerve disorders in the brain. ${ }^{11}$

Neonatal stress could occur due to maternal death which caused the hypothalamus-pituitary-adrenal (HPA) activation to secrete glucocorticoids which were the initial sign of stress. Synapsin-I was involved in the critical development initial process of the nervous system. The stress impact on early neuronal development in the brain could reduce cognitive function with symptoms of dendritic atrophy and loss of synapses. ${ }^{10,12}$ The thought of the maternal deaths impact should not only be on ways to reduce maternal mortality. Maternal health was also an important thing to note, not just for the mother survival, but it was also important for the continuity of brain growth during the golden age in the first 1,000 days of the child's life as a preparation to face the future changes challenges. Based on this background, this study was conducted to the impact of maternal separation as a maternal death model on the cerebrum and cerebellum synapsin-I expression of 3 days old Rattus norvegicus.

\section{Material and Method}

This study was true laboratory experimental designs with randomized post test only control group design. The study was conducted from February to May 2019 at the Laboratory of the Veterinary Medicine Faculty, Airlangga University. The samples of this study were Rattus norvegicus mother and the unit samples were 3 days old Rattus norvegicus. All animals try to be acclimatized before being pregnant. Superovulation of female rats was done by injecting 10 IU of PMSG (Folligon $^{\mathrm{TM}}$, Intervet Boxmeer, Holland), 48 hours later, the injection $10 \mathrm{IU}$ of HCG (Chorulon ${ }^{\mathrm{TM}}$, Intervet Boxmeer, Holland) was carried out and the mother was immediately mated monomating. 17 hours after monomating, a vaginal plug examination was performed to ensure pregnancy. ${ }^{13}$ Pregnant female Rat was taken randomly into 2 groups, each group consisting 18 pregnant female $R$ at.

The maternal mortality model study group was divided into 2 groups, the control group (K1) consisting of newborn Rattus norvegicus which remained with the mother until the 3 days old and the treatment group (K2) consisting of newborn Rattus norvegicus separated from mother to 3 days old that were given animal milk formula (Esbilac ${ }^{\circledR}$ Powder, Pet-Ag Inc, Hampshire). From each parent, Rattus norvegicus pups were taken with the heaviest, medium and lowest weights.

Imonohistochemical examination with synapsin-I antibodies was assessed semi-quantitatively on the scale of Rammele-Stegner using the Immuno Reactive Score (IRS). ${ }^{14}$ Statistical analysis uses IBM SPSS Statistic 20. Data with normal distribution was tested by Independent $\mathrm{T}$ test. If the data was not normally distributed, the data was tested by the Mann Whitney test. This study uses a significance level of 0.05 with a confidence level of $95 \%$.

\section{Findings}

Table 1: The mean and standard deviation of the Cerebrum synapsin-I expression

\begin{tabular}{|c|c|c|}
\hline Group & n & Synapsin-I Expression (IRS) \\
\hline & & Mean \pm Standard Deviation \\
\hline K1 & 18 & $4,08 \pm 1,45$ \\
\hline K2 & 18 & $2,35 \pm 1,22$ \\
\hline
\end{tabular}

The results showed a mean of cerebrum synapsin-I expression in the treatment group was $2,35 \pm 1,22$ and a control group was $4,08 \pm 1,45$. 
Table 2: Mann Whitney Analysis Results of Cerebrum Synapsin-I expression

\begin{tabular}{|c|c|c|c|}
\hline \multicolumn{2}{|c|}{ Group } & p Value & Different test analysis \\
\hline $\mathrm{K} 1$ & $\mathrm{~K} 2$ & $0,000^{*}$ & Mann Whitney Test \\
\hline
\end{tabular}

*Significantly different $p<0,05$

Analysis of the Mann Whitney test showed that there were significant differences in the synapsin-I expression between the control and treatment groups with a value of $\mathrm{p}=0,000(\mathrm{p}<0,05)$.
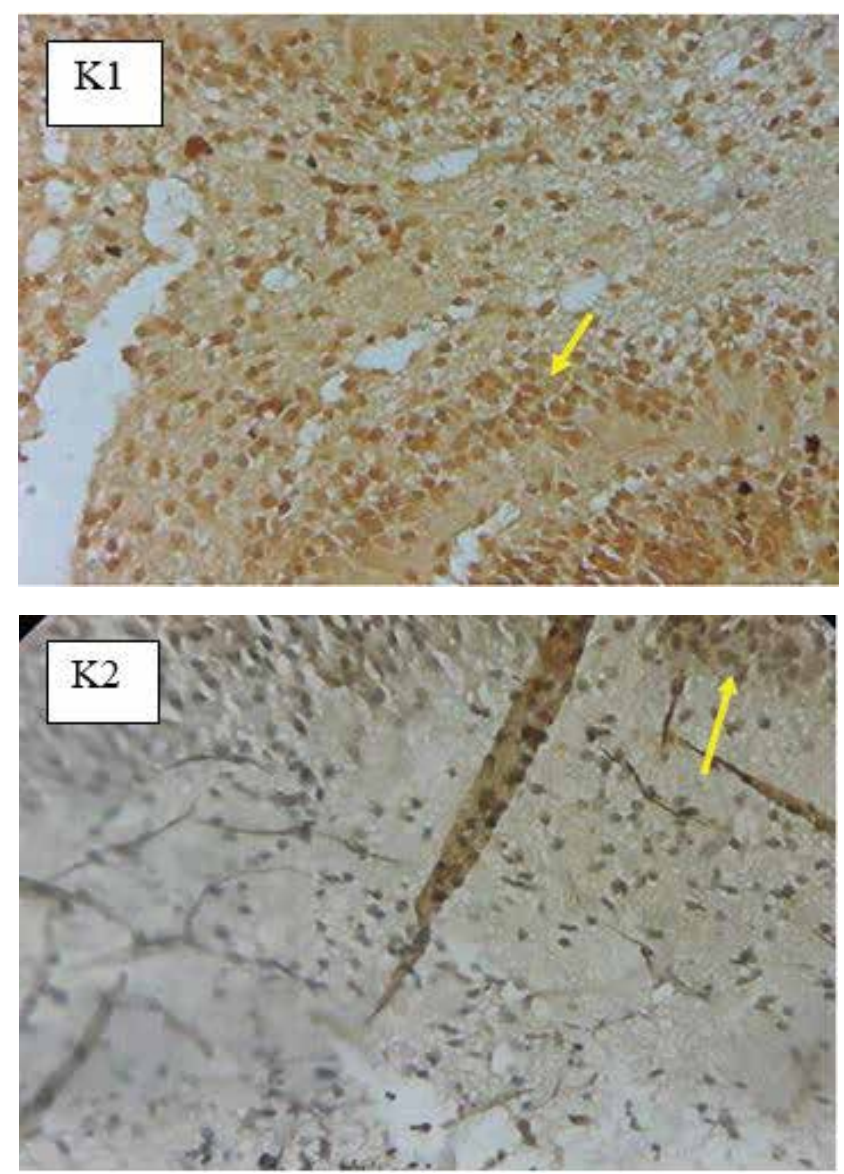

Figure 1: Comparison of synapsin I expressions represented by chromogen brown color on the cerebrum tissue, yellow arrows showing the maximum expression area using immunohistochemical staining, 400x magnification; Miconos microscope MCX50LED; Optilab Plus camera

Table 3: Mean and standard deviation of Cerebellum synapsin-I expression

\begin{tabular}{|c|c|c|}
\hline \multirow{2}{*}{ Group } & \multirow{2}{*}{$\mathbf{n}$} & \multicolumn{2}{|c|}{ Synapsin-I Expression (IRS) } \\
\cline { 3 - 3 } & & Mean \pm Standard Deviation \\
\hline K1 & 18 & $3,80 \pm 1,21$ \\
\hline K2 & 18 & $2,22 \pm 1,00$ \\
\hline
\end{tabular}

The examination results of the cerebellum Synapsin-I expression showed a mean and standard deviation in the treatment group was 2,22 $\pm 1,00$ and the control group was $3,80 \pm 1,21$.

Table 4: Results of Independent T Analysis of Cerebellum Synapsin-I expression

\begin{tabular}{|c|c|c|c|}
\hline \multicolumn{2}{|c|}{ Group } & p Value & Different test analysis \\
\hline K1 & K2 & $0,000^{*}$ & Independent $T$ \\
\hline
\end{tabular}

*Significantly different $\mathrm{p}<0,05$

The results of the Independent $T$ test showed that there was a significant difference in the synapsin-I expression between the control and treatment groups with a value of $p=0,000(p<0,05)$.
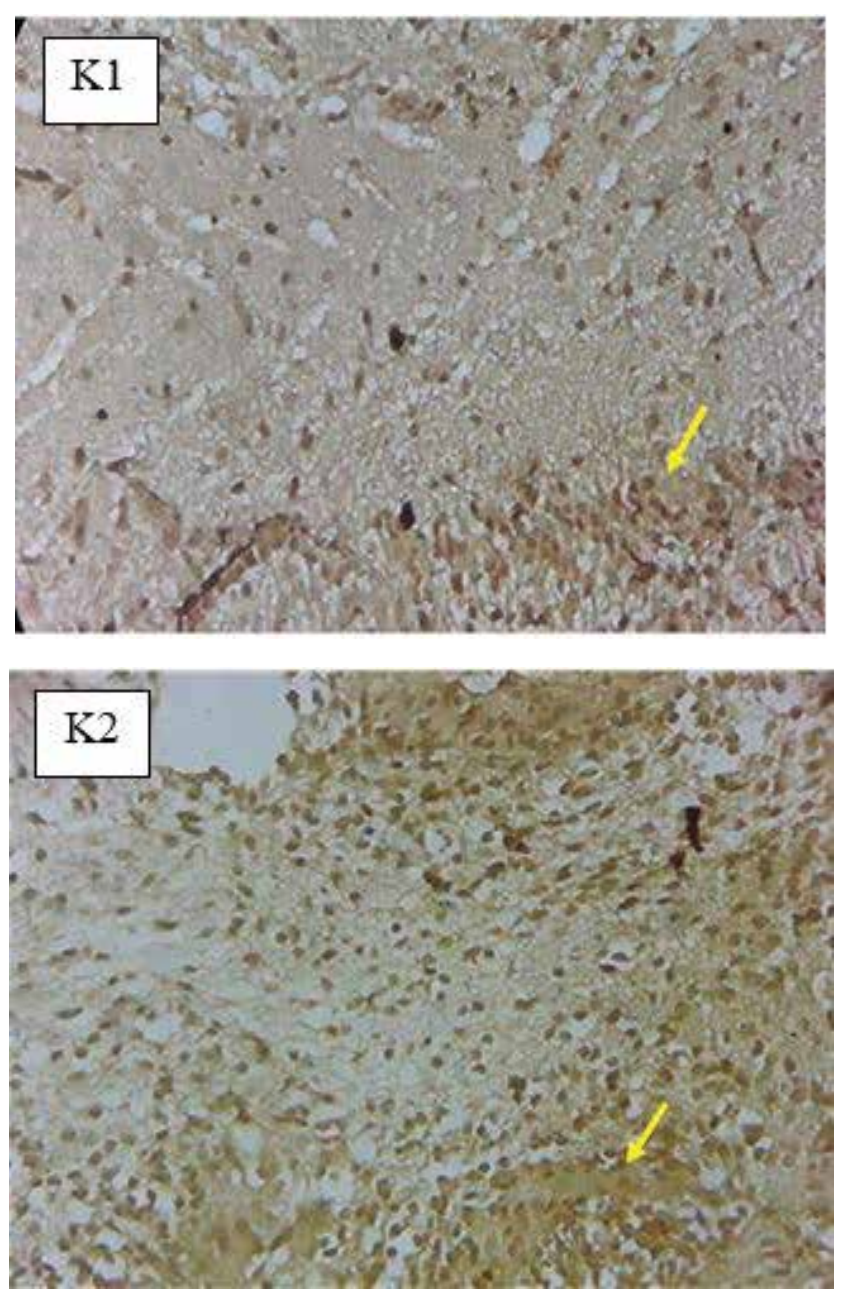

Figure 2: Comparison of synapsin I expressions represented by chromogen brown color on the cerebellum tissue, yellow arrows showing the maximum expression area using immunohistochemical staining, 400x magnification; Miconos microscope MCX50LED; Optilab Plus camera 


\section{Discussion}

The results of this research indicate the mean expression of cerebrum and cerebellum Synapsin-I 3 days old Rattus norvegicus with maternal separation was lower than without maternal separation. The results study of the examination used microarray analysis for stress at the beginning of life was carried out by maternal separation on day 14-21, while still providing water and feed nutrients, indicating that separation from the parent reduced synapsin-I mRNA gene expression in the Rat pup's amygdale. Maternal separation in animals shows an increase in high expression of corticotrophinrealizing-hormone $(\mathrm{CRH})$ and glucocorticoid receptors. ${ }^{15}$ Glucorticoids could directly reduce the expression of synapsin-I and EGR-1 transcription in the hippocampus. ${ }^{16}$ The results of examination on 9-months-old babies who separated from their mothers for 30 minutes showed an increase in glucorticoids levels compared to 30 minutes when babies interacted and played with mothers. Maternal separation increases glucorticoids and ACTH in animals. 9 and 12-days-old rodent show high ACTH and corticosterone. ${ }^{17}$ Therefore, the timing and quality of interaction with mother plays a role in the development of the Axis HPA. If there was a maternal death, the contact interaction between the parent and child would be lost then causing early life stress.

The most rapid brain neuron development in the first 1,000 days of life. Synapsin-I is a protein that plays a role in synaptic transmission and plasticity in the presynaptic mechanism. The combined action of synapses that work in different areas of the brain eventually forms brain functions such as learning and memory. ${ }^{18}$ Synapsin-I was associated with axon growth and regulation of synaptic vesicles kinetics fusion. Both synapsin-I isoforms function in synapse formation and minimize depletion of neurotransmitters in synapse inhibition by contributing to the retention of synaptic vesicles. Synapsin-I also plays a role in synaptogenesis and modulates the release of neurotransmitters. Changes in synaptic vesicles in the presynaptic terminal could result in reduced release of neurotransmitters and delayed recovery of synaptic transmission after depletion of neurotransmitters. ${ }^{11}$

Immunoreactivity examination of synapsin-I was performed as a direct marker of the synapses presence in the central nervous system. Cerebrum acted in cognitive and affective function. Synapsin-I in the cerebrum was expressed in neurophil, whereas in neurons and dendrites there was little synapsin-I expression. Cerebellum played a role in motor, cognitive, emotional, and behavioral development. In the cerebellum, synapsin-I could be expressed in the molecular layer of the cerebellum cortex, i.e. in the nucleus and cytoplasm of the granular and granular layers of the synaptic complex..$^{9,19}$

Early life stress which was induced by glucocorticoids caused a decrease in cognitive abilities, including damage to work and nonverbal memory, mental flexibility, and information processing. Symptoms included dendritic atrophy and loss of synapses in neurons. Glucocorticoids mediated cellular or molecular effects on synapses and dendrites through glucocorticoid receptor (GR) and mineralocorticoid receptor (MR). In the brain, GR which had been activated by GC could directly bound to BDNF/ CREB in response to stress and would reduced BDNF expression. BDNF bound to TrkB (Tropomyosin related kinase B) in postsynaps and presynaps which caused activation involving 2 pathways, namely phospholipase (PLC)-Ca ${ }^{2+}-\mathrm{CaMKII}$ and Ras-Raf-MAPK for regulation of synapsin-I expression. When stress and glucorticoid increase occured, the MAPK activation stimulated CAMKII to reduce transcription of EGR-1 and lower synapsin-I expression. ${ }^{20,21}$ Synapsin-I regulation could also pass IGF-1, IGF-1 pathway (Insulin like growth factor-1) which would bound to IGF1R and activated two signaling pathways similar to BDNF to regulate the regulation of synapsin-I expression directly. If there was an increase in GC and activation of GR, IGF-1 inhibition would resulted in a lower expression of synapsin-I. ${ }^{20,22}$

Early life stress in the brain was also related to oxidative stress due to an imbalance between ROS and antioxidants. ROS results in GC receptor translocation from the cytoplasm to the nucleus which disrupted the receptor function. Imbalance in mitochondria produces NADPH oxidase (NOX). ROS in the brain was caused by NOX enzymes according to cellular stressors. In addition, many stress signaling pathways such as ERK1, p38 MAPK were activated following NOX stimulation which would affected cell damage which might directly result in lower synapsin-I expression..$^{21,23}$ Apart from In this pathway, synapsin-I expression could be directly affected by glucocorticoids via EGR-1. ${ }^{16}$ Decreases synapsin-I expression which included several pathways, namely EGR-1, BDNF, IGF-1, and could also be affected by oxidative stress. 


\section{Conclusion}

Cerebrum and cerebellum Synapsin-I expression of 3 days old Rattus norvegicus with maternal separation as maternal death model was lower than 3 days old Rattus norvegicus without maternal separation as maternal death model.

Ethical Clearance: Ethical clearance of this study was taken from Ethical Committee of the Faculty of Veterinary Medicine, Airlangga University Surabaya Indonesia. Number: 2.KE.041.04.2019.

Source of Funding: This study was self funding by authors.

Conflict of Interest: The authors have no conflicts of interest.

\section{REFERENCES}

1. Reid A, Garrett E. Medical provision and urbanrural differences in maternal mortality in late nineteenth century Scotland. Social Science \& Medicine 201. 2018; 0: 25-43.

2. Scott S, Kendali L, Gomez P, Howie SR, Zaman SM, Caesay S, Alessandro DU, Jasseh M. Effect of maternal death on child survival in rural West Africa: 25 years of prospective surveillance data in the Gambia. PLoS ONE. 2017 Feb 22; 12(2): $1-14$.

3. Geller SE, Koch AR, Garland CE, Mcdonald EJ, Storey F, Lawton B. A global view of severe maternal morbidity: moving beyond maternal mortality. Reproductive Health. 2018; 15(98): $1-13$.

4. Health Ministry of Republic Indonesia. Indonesia Health Profile in 2016. 2016 [cited from 20 August 2018]. Available from : http://www.depkes.go.id/ resources/download/pusdatin/profil-kesehatanindonesia/Profil-Kesehatan-Indonesia-2016.pdf

5. Health Ministry of Republic Indonesia. This is the Performance Achievement of the Health Ministry of Indonesian in 2015 - 2017 [internet]. 2017 [cited from 17 August 2018]. Available from: http://www.depkes.go.id/article/ view/17081700004/-inilah-capaian-kinerjakemenkes-ri-tahun-2015--2017.html.
6. East Java Health Departement. Health Profile of East Java Province in 2016 [internet]. 2016 [cited 11 January 2019]. Available from : http://www.depkes.go.id/resources/download/ profil/PROFIL KES PROVINSI 2016/15 Jatim 2016.pdf

7. Angelhoff C, Blomqvist YT, Helmer CS, Olsson E, Shorey S, Frostell A, Morelius E. Effect of skin-to-skin contact on parents' sleep quality, mood, parent-infant interaction and cortisol concentrations in neonatal care units: study protocol of a randomised controlled trial. BMJ Open. 2018;8:1-8.

8. Hermanto TJ. Bersujud Dalam Rahim 2: Mencerdaskan Janin Sejak Dalam Rahim dengan Kombinasi Stimulasi 11-14 Musik Karya Mozart Dan Nutrisi. Surabaya: Global Persada Press. 2013.

9. Pieterman K, Batalle D, Dudink J, Tournier JD, Huges EJ, Barnett M, Benders MJ, Edwards AD, Hoebeek FE, Counsel SJ. Cerebello-cerebral connectivity in the developing brain. Brain Struct Funct. 2016 August 21; 222: 1625-1634.

10. Brenes O, Giachello CN, Corradi AM, Ghirardi M, Montarolo PG. Synapsin Knockdown was Associated With Decreased Neurite Outgrowth, Functional Synaptogenesis Impairment, and Fast High-Frequency Neurotransmitter Release. Journal of Neuroscience Research. 2015; 93:1492-1506.

11. Mirza FJ, Zahid S. The Role of Synapsins in Neurological Disorders. Neurosci. Bull. 2017 December 27;34(2): 349-358.

12. Anderson DE, Patel DA. Infants born preterm, stress, and neurodevelopment in the neonatal intensive care unit: might music have an impact? Developmental Medicine \& Child Neurology. 2017; 1-10.

13. Widjiati, Dewita, Hendrawan VF., Purwantari KE, Wadji SA, Zulfarniansyah AB, Putri AS, Rahmawati MA, Al-Ilmi MF. Histopathologic changes in liver tissue from cadmium intoxicated mice and treated with curcumin during pregnancy. Research J. Pharm. and Tech. 2018 March; 11(3): 863-865. 
14. Thaiss W, Kaufmann S, Kloth C, Nikolau K, Bosmuler H, Horger M. VEGFR-2 expression in HCC, dysplastic and regenerative liver nodules, and correlation with pre-biopsy Dynamic Contrast Enhanced CT. European Journal of Radiology. 2016; 85:2037.

15. Park HJ, Kim SK, Kang WS, Chung JH, Kim JW. Increased activation of synapsin 1 and mitogen-activated protein kinases/extracellular signal-regulated kinase in the amygdala of maternal separation rats. CNS Neuroscience \& Therapeutics. 2014;20: 172-181

16. Revest JM, Kaouane N, Mondin M, Roux AL, Pont F, Valle M, Barik J, Tronche F, Desmedt, A, Piazza P. The enhancement of stress-related memory by glucocorticoids depends on synapsinIa/Ib. Molecular Psychiatry. 2010;15: 1140-1151.

17. Leber SMM, Brummelte S. Neonatal pain and reduced maternal care: early-life stressors interacting to impact brain and behavioral development. Neuroscience 342. 2017; 0: 21-36.

18. Cesca F, Baldelli P, Valtorta F, Benfenati F. 2010. The synapsins: Key actors of synapse function and plasticity. Progress in Neurobiology 91. 2010; 0: 313-348.
19. Thonsranoi K., Glaharn S, Punsawad C, Chaisri U, Krudsood S, Viriyavejakul P. Increased synapsin-I expression in cerebral malaria. Int $\mathrm{J}$ Clin Exp Pathol. 2015;8(11): 13996-14004.

20. Finsterwald C, Alberini C. Stress and glucocorticoid receptor-dependent mechanisms in long-term memory: from adaptive responses to psychopathologies. Neurobiol Learn Mem. 2014 July; 0: 17-29.

21. Marte A, Messa M, Benfanati F, Onofri F. 2016. Synapsins were Downstream Players of the BDNF-Mediated Axonal Growth. Mol Neurobiol. 2016 January $07 ;$ 0:1-11.

22. Cheng Q, Song, SH, Augustine GJ. Calciumdependent and synapsin-dependent pathways for the presynaptic actions of BDNF. Frontiers in Cellular Neuroscience. 2017 March 24; 11(75):1-12.

23. Schiavone S, Colaianna M, Curtis L. Impact of early life stress on the pathogenesis of mental disorders: relation to brain oxidative stress. Current Pharmaceutical Design. 2015; 21:14041412. 